\title{
Measurement of cardiac output by thermal dilution in infants and children
}

\author{
S. D. W Y S E, J . P F I T Z N E R, A . R E E S, \\ J . C.R. L I N C O L N, a n d \\ M. A. B R A N T H W A I T E
}

Brompton Hospital, London SW3

\begin{abstract}
Wyse, S. D., Pfitzner, J., Rees, A., Lincoln, J. C. R., and Branthwaite, M. A. (1975). Thorax, 30, 262-265. Measurement of cardiac output by thermal dilution in infants and children. The accuracy of the thermal dilution technique for measuring cardiac output in infants and children has been assessed by comparison with the direct Fick technique. Satisfactory correlation between the two methods has been demonstrated, and it is concluded that a commercially available monitor can be used to determine cardiac output by thermal dilution in acutely sick infants and children. The volume of injectate should be selected according to the weight of the child, and the value displayed by the monitor should be adjusted by the appropriate fraction.
\end{abstract}

Techniques for the measurement of cardiac output by thermal dilution have been described for use in both animals (Fegler, 1954; Goodyer et al., 1959; Evonuk et al., 1961; Hosie, 1962; Korner, 1965) and man (Khalil, 1963; Branthwaite and Bradley, 1968; Ganz et al., 1970), and the advantages and accuracy of the method are recognized widely (Singh et al., 1970; Olsson et al., 1970). The method employed most commonly depends upon the measurement of temperature change in the pulmonary artery after the injection of room temperature dextrose or saline solution into the right atrium through a short catheter in the internal jugular vein. Recirculation does not occur in adult patients (Hill, 1970), and simple integration of the area under the curve enables the calculation of cardiac output to be completed rapidly. Apparatus which has been designed to carry out these functions automatically (Cowell and Bray, 1970 ) is now available commercially ${ }^{1}$.

In the series reported by Branthwaite and Bradley (1968), comparison between the thermal dilution and Fick techniques in man resulted in a correlation coefficient of 0.99 and a regression equation of the form $y=0.9617 x-0.2007$ where $y$ and $x$ are values for cardiac output derived by the Fick and thermal dilution methods respectively. This equation has been used in the con-

\footnotetext{
${ }^{1}$ Devices Ltd. (now Cardio-Vascular Instruments Ltd.)
}

struction of the commercially available apparatus so that the value displayed for cardiac output is corrected for the dead space of the injectate $\overrightarrow{7}$ catheter and for the small unmeasured heat loss across its wall and into surrounding tissues. The apparatus was designed for use with adult patients and assumes an injectate volume of $10 \mathrm{ml}$ room temperature dextrose solution. Repeated injection of this volume into infants or young childrers could exceed daily fluid requirements, and re 3 . circulation might occur if the thermal indicatori were not dissipated in the tissues within one circulation.

A study has been undertaken to establish? whether accurate and repeatable results can obtained using small volumes of injectate, and the validity of values derived by calculating thes appropriate fraction of the value displayed on the meter of the commercial monitor has been assessed.

MATERIAL AND METHODS

Ten children were studied within the first $1 \frac{200}{80}$ hours following open-heart surgery. Details of age and weight are given in the Table. Routine preoperative preparation included placement of \& cannula in the radial artery and percutaneou\& insertion of a parallel-sided Teflon cannula (Cannula $8.2 \mathrm{~cm}$; internal diameter $1.0 \mathrm{~mm}$; exহ ternal diameter $1.4 \mathrm{~mm}$ ) up to its hub into thes 
T A B L E

CLINICAL DETAILS AND RESULTS OF COMPARISON BETWEEN AUTOMATED THERMAL DILUTION AND FICK TECHNIQUES

\begin{tabular}{|c|c|c|c|c|}
\hline Age (years) & Weight (kg) & $\begin{array}{l}\text { Fick Cardiac Output } \\
\text { (mean of } 2 \text { readings) }\end{array}$ & \multicolumn{2}{|c|}{$\begin{array}{l}\text { Thermo-dilution Cardiac Output } \\
\text { Mean } \pm \text { SEM }\end{array}$} \\
\hline $\begin{array}{l}5 \\
4 \\
5 \\
0 \cdot 4 \\
2 \\
2 \\
1 \cdot 9 \\
0 \cdot 9 \\
0 \cdot 8 \\
2\end{array}$ & $\begin{array}{r}17.6 \\
17.2 \\
13.8 \\
5.8 \\
10.7 \\
10.6 \\
6.0 \\
5.9 \\
7 \cdot 1 \\
8.5\end{array}$ & $\begin{array}{l}2 \cdot 8 \\
2 \cdot 8 \\
2 \cdot 8 \\
0 \cdot 5 \\
1 \cdot 8 \\
2 \cdot 0 \\
1 \cdot 2 \\
1 \cdot 4 \\
1 \cdot 5 \\
1 \cdot 3\end{array}$ & $\begin{array}{l}2.2 \pm 0.07 \\
2.6 \pm 0.14 \\
3.0 \pm 0.07 \\
0.6 \pm 0.02 \\
1.3 \pm 0.04 \\
2.3 \pm 0.03 \\
1.0 \pm 0.03 \\
1.4 \pm 0.12 \\
1.3 \pm 0.08 \\
1.4 \pm 0.07\end{array}$ & $\begin{array}{l}n=6 \\
n=5 \\
n=5 \\
n=4 \\
n=3 \\
n=3 \\
n=3 \\
n=4 \\
n=3 \\
n=7\end{array}$ \\
\hline
\end{tabular}

right internal jugular vein. A Devices thermal sensing catheter $(50 \mathrm{~cm} ; 3 \mathrm{~F} ; 90 \%$ thermal response time $300 \mathrm{msec}$ ) was positioned in the pulmonary artery during the closing stages of the operation in anticipation of the need for clinical monitoring in the postoperative period. Each child was maintained on intermittent positive pressure ventilation throughout the study using a Brompton-Manley ventilator which delivered a mixture of oxygen and air through a well-fitting, oral endotracheal tube. In each case the tube was checked for leaks in the usual way.

Measurements of cardiac output by thermal dilution were carried out using $5 \%$ dextrose solution at room temperature which was injected through the internal jugular cannula. The volume of injectate was selected according to the formula $(10 / 70 \times$ body weight in $\mathrm{kg})$; this figure was adjusted to the nearest $0.5 \mathrm{ml}$, and the injectate volume varied between $1 \mathrm{ml}$ and $2.5 \mathrm{ml}$ in all but one child weighing $17.6 \mathrm{~kg}$ in which an injectate volume of $5 \mathrm{ml}$ was chosen without reference to the formula. The value for cardiac output displayed on the meter was multiplied by the factor (injectate volume/10) to obtain a corrected value for cardiac output, and on each occasion at least three measurements were made in quick succession.

In five patients the thermal dilution curve was recorded photographically using a New Electronic Products recorder, and the cardiac output was calculated manually using the equation

$V \times D_{1} \times S_{1} \times\left(T_{b}-T_{1}\right)=Q \times d T \times t \times D_{b} \times S_{b} \times 1000 / 60$ where $\mathrm{V}=$ volume of injectate corrected for catheter dead space $(0.1 \mathrm{ml})$

$\mathrm{D}=$ density of injectate (i) and blood (b) respectively

$\mathrm{S}=$ specific heat of injectate (i) and blood (b)

$\mathrm{T}=$ temperature of injectate (i) and blood in pulmonary artery (b)

$\mathrm{dT}=$ average temperature change

$$
\begin{aligned}
\mathrm{t} & =\begin{array}{l}
\text { duration of temperature change in } \\
\text { seconds }
\end{array} \\
\mathrm{Q} & =\text { cardiac output in litres per minute. }
\end{aligned}
$$

The integral of change of temperature against time was derived by summing the area under the curve and comparing this with the area of a known temperature-time change. Values for body temperature and injectate temperature were obtained from the cardiac output monitor at the time of each measurement, and the density and specific heat of blood and $5 \%$ dextrose solution were derived from tables, assuming a normal concentration of plasma proteins but making allowance for the effect of a change in haematocrit on the density of blood (van Slyke et al., 1950).

The cardiac output was also determined by the Fick technique. Expired air was collected over timed periods of approximately three minutes' duration which began and ended at the same point in the ventilator cycle. A valve designed specifically for this purpose (Pfitzner, 1975) was employed to separate compression volume from the true expired volume.

The oxygen concentration of the dry gas supplied to the ventilator was measured with a paramagnetic analyser (Servomex, OA 150) coupled to a digital voltmeter (Bradley Electronics Ltd.), and the expired oxygen concentration was determined with the same apparatus by syringing known volumes of the gas, saturated at room tempera- ture, through the analyser until a constant reading was obtained. The expired carbon dioxide concentration was measured using the carbon dioxide electrode of a Radiometer BMS3 electrode system which had been calibrated with known gas mixtures. The remaining volume of expired gas was determined by evacuating each Douglas bag with a calibrated syringe.

Samples of pulmonary and systemic arterial blood were withdrawn into heparinized $2 \mathrm{ml}$ syringes during each gas collection. These were 
stored in ice until analysed for oxygen content using a Lex- $\mathrm{O}_{2}$-Con (Lexington Instrument Company). Two determinations of cardiac output by the Fick technique were made in succession, employing an arrangement of stopcocks which permitted the collection of expired gas in one or other of a pair of Douglas bags which were both flushed and evacuated before the study began. On most occasions a second operator carried out the thermal dilution measurements while the gas collections were being made (but not while pulmonary arterial blood was being sampled), but when the study was carried out by a single operator a set of three thermal dilution measurements was made both before and after the pair of gas collections.

Standard equations were used to derive oxygen consumption and cardiac output. Regression equations were calculated to determine both the degree of correlation between the manual and automated methods for measuring cardiac output by thermal dilution and the correlation between the mean values for cardiac output derived automatically by the thermal dilution technique and the corresponding determination by the Fick technique.

All the individual values for cardiac output which were obtained automatically by the thermal dilution method were expressed as a percentage of the mean for each patient, and these percentage figures were then analysed for variance to determine the reproducibility of the method.

\section{RESULTS}

There was no systematic difference between values for cardiac output determined by the manual or automated thermal dilution methods. In two cases technical difficulties with the recording apparatus prevented satisfactory 'manual' analysis of some curves, but the correlation coefficient based on 12 measurements in five patients was 0.92 . The regression equation was $y=0.74+0.53$ where $y$ and $x$ represent the manual and automated values.

Detailed results of the comparison between the automated thermal dilution and Fick techniques are presented in the Table and the Figure. There was a very highly significant correlation between the two methods $(r=0.93 ; \mathrm{p}<0.001)$. The regression equation was found to be $y=0.9445 x+0.1899$ where $y$ and $x$ represent the Fick and automated thermal dilution values respectively. The standard error of the regression coefficient was $0 \cdot 1334$.
Forty-three values for cardiac output deter $\frac{\overrightarrow{\vec{S}}}{-\frac{\vec{f}}{0}}$ mined automatically by the thermal dilution: technique were expressed as a percentage of the appropriate mean. The standard deviation of this series was $\pm 8.57 \%$.

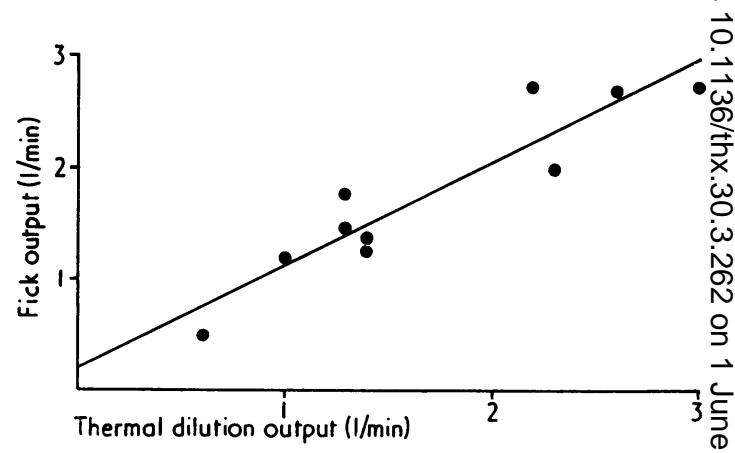

FIGURE Regression line and values for cardiac outputo determined by the direct Fick and thermal dilution methods.

\section{DISCUSSION}

It was anticipated that a number of difficulties气 might limit the accuracy of the thermal dilution technique in small children. Recirculation can beō detected if excessive doses of cold indicator are injected, and errors in the measurement of each dose are of greater importance when small volumes of injectate are used. The thermal dilution curves are inscribed very rapidly in children and apparent loss of indicator would result if the response time of the thermal sensing catheter were inadequate. The commercial monitor is adjusted to allow for an injectate catheter dead space of $0.3 \mathrm{ml}$, and for unmeasured heat losses both across the wall of a $20 \mathrm{~cm}$ nylon catheter of in $\frac{5}{5}$ ternal diameter $0.75 \mathrm{~mm}$ and into surrounding tissues. The dimensions of the apparatus used in the present study differed considerably, and it was feared that proportionate reduction of the valuen for cardiac output displayed on the scale of the monitor would introduce a further error.

In practice, none of these problems appeareck to be of major importance. Satisfactory correla $\frac{0}{c}$ tion was obtained between the values for cardiaces output derived from the commercial monitor and those obtained by the laborious manual techniquee of summing the area under the curve, and, of evert greater practical value, there was good correlation $\frac{\text { के }}{\overline{0}}$ between values derived automatically by thermak dilution and those obtained with the Fick technique. 
The reproducibility of the individual thermal dilution values in the present series $( \pm 8.57 \%)$ compares favourably with the direct Fick technique (Yang et al., 1972). The simplicity, safety, and speed of the method allow multiple measurements to be made in quick succession, and greater accuracy can be obtained easily by calculating the mean of at least three measurements.

It can be concluded that the thermal dilution technique is a reliable method for the determination of cardiac output in acutely sick infants and children. The volume of injectate should be selected according to the weight of the child, and the Devices cardiac output monitor can be used provided that allowance is made for the reduced volume of injectate.

SDW was supported by a grant from the Board of Governors, National Heart and Chest Hospitals, and JP was in receipt of a grant from the British Heart Foundation.

\section{REFERENCES}

Branthwaite, M. A. and Bradley, R. D. (1968). Measurement of cardiac output by thermal dilution in man. Journal of Applied Physiology, 24, 434.

Cowell, T. K. and Bray, D. G. (1970). Measuring the heart's output. Electronics and Power, 16, 150.

Evonuk, E., Imig, C. J., Greenfield, W., and Eckstein, J. W. (1961). Cardiac output measured by thermal dilution of room temperature injectate. Journal of Applied Physiology, 16, 271.

Fegler, G. (1954). Measurement of cardiac output in anaesthetised animals by a thermo-dilution method. Quarterly Journal of Experimental Physiology, 39, 153.

Ganz, W., Donoso, R., Forrester, J. S., Marcus, H. S., and Swan, H. J. C. (1970). Comparison of simultaneous dye- and thermal-dilution cardiac outputs in dogs and man. American Journal of Cardiology, 25, 97.

Goodyer, A. V. N., Huvos, A., Eckhardt, W. F., and Ostberg, R. H. (1959). Thermal dilution curves in the intact animal. Circulation Research, 7, 432.

Hill, D. W. (1970). Electronic Measurement Techniques in Anaesthesia and Surgery. Butterworths, London.

Hosie, K. F. (1962). Thermal-dilution technics. Circulation Research, 10, 491.

Khalil, H. H. (1963). Determination of cardiac output in man by a new method based on thermodilution. Lancet, 1, 1352.

Korner, P. I. (1965). The effect of section of the carotid sinus and aortic nerves on the cardiac output of the rabbit. Journal of Physiology, 180, 266.

Olsson, B., Pool, J., Vandermoten, P., Varnauskas, E., and Wassen, R. (1970). Validity and reproducibility of determination of cardiac output by thermodilution in man. Cardiology, 55, 136.

Pfitzner, J. (1975). Continuous positive airway pressure: the collection of expired gases. Anaesthesia (In press).

Singh, R., Ranieri, A. J. Jr, Vest, H. R. Jr, Bowers, D. L., and Dammann, J. F. Jr. (1970). Simultaneous determinations of cardiac output by thermal dilution, fiberoptic and dye-dilution methods. American Journal of Cardiology, 25, 579.

van Slyke, D. D., Phillips, R. A., Dole, V. P., Hamilton, P. B., Archibald, R. M., and Plazin, J. (1950). Calculation of hemoglobin from blood specific gravities. Journal of Biological Chemistry, 183, 349.

Yang, S. S., Bentivoglio, L. G., Maranhao, V., and Goldberg, H. (1972). From Cardiac Catheterization Data to Hemodynamic Parameters. F. A. Davis, Philadelphia.

Requests for reprints to: Dr. M. A. Branthwaite, Brompton Hospital, Fulham Road, London SW3 6HP. 